\title{
Navegando em águas brasileiras: NOTAS SOBRE A VIAGEM DO FRANCÊS PYRARD DE LAVAL À COLÔNIA BRASILEIRA (1610-1611)*
}

\author{
Sailing in Brazilian waters: the information from French \\ Pyrard of Laval on the Brazilian colony (1610-1611)
}

\author{
Maria Isabel de Siqueira ${ }^{1}$ \\ Thiago de Souza dos Reis ${ }^{2}$
}

RESUMO

A presença dos viajantes/navegadores em terras americanas após a conquista contribuiu para a circulação de informações úteis acerca do potencial dessas regiões. Os recursos naturais que as novas terras possuíam despertaram o interesse dos europeus nesses produtos visando o comércio. A visita oficial ou não de viajantes a essas terras resultou em registros das condições da terra, seus hábitos e sobre a obediência ou não às leis elaboradas pelas metrópoles para o controle das suas colônias. Nossa proposta nestas notas de pesquisa é identificar nos relatos deixados por Pyrard de Laval, escrito no início do século XVII, os hábitos, os costumes, as leis, a organização das cidades, enfim a conduta social e as relações entre Estado e sociedade na colônia portuguesa da América. Neste sentido, procuramos compreender, a partir da contribuição do autor sobre a exploração dos recursos naturais e das práticas agrícolas nos arredores da Baía de Todos os Santos, as relações lícitas e ilícitas desta dinâmica social.

Palavras-chave: Período filipino. Práticas agrícolas. Recursos naturais. Viajantes.

\section{ABSTRACT}

The presence of travelers/sailors in American lands after the conquest contributed to the circulation of useful information about the potential of these regions. The natural resources that the new lands had

* Este artigo conta com o apoio da Faperj, através do Edital de Apoio a Projetos de Pesquisa na Área de Humanidades 2011.

1 Professora Associada do Departamento e da Pós-Graduação em História da Universidade Federal do Estado do Rio de Janeiro.

2 Professor da graduação em História da Universidade Estácio de Sá e da graduação em Direito da Universidade Veiga de Almeida. Doutorando em História pela Universidade Federal do Estado do Rio de Janeiro. 
aroused the interest of Europeans in these products targeting the trade. The official (or unofficial) visit of travelers to these lands resulted in records of the conditions of the earth, and their habits of obedience towards the laws enacted by cities to control their colonies. Our purpose in these notes is to identify the narrative of Pyrard de Laval, written in the early seventeenth century, the habits, the customs, the laws, the organization of cities, and finally the social behavior and relations between State and society in the Portuguese colony of America. In this sense, we understand, from the contribution of the author on the exploitation of natural resources and agricultural practices in the vicinity of the Baía de Todos os Santos, licit and illicit relations of this social dynamic.

Keywords: Philippine period. Natural resources. Agricultural practices. Sailors.

Dentre as possibilidades que os soberanos tinham de conhecerem o mundo colonial, podemos destacar as informações oficiais fornecidas pelas autoridades coloniais, como as cartas trocadas entre a Coroa e os governadores das capitanias, os requerimentos que pediam providências para a exploração de descoberta de minas, as denúncias sobre o mau procedimento de administradores locais, os memoriais, "os inventários da geografia, da natureza e das comunidades" (RAMINELLI, 1962:26), os relatos, as crônicas, os diários, entre outras formas que davam as autoridades notícias sobre os espaços e realidades coloniais. Sabemos que os debates sobre os gêneros das chamadas "narrativas de viagens" é amplo e neste sentido, destacamos as informações advindas dos relatos escritos dos viajantes que, não deixaram de registrar as suas viagens costa a costa e interior das colônias americanas ou a outras partes do globo, por conta própria ou a serviço do rei.

Dessa forma, o monarca era informado, em um primeiro momento, sobre o potencial das regiões, das possíveis riquezas e, no caso de colônias já estabelecidas, tomavam conhecimento do progresso da conquista e sobre a obediência ou não às suas leis. Quando intencionalmente a viagem era realizada, a contrapartida da empreitada da narrativa era o reconhecimento da parte do rei e/ou o recebimento de privilégios e mercês aos que se aventuravam.

Concordamos com Claudia Santos (2013: 20-21) quando ela registra que

se os viajantes já não são a fonte mais importante para a historiografia, o seu uso não desapareceu completamente. Certos aspectos desses relatos talvez expliquem o seu uso persistente; a variedade de autores de diferentes nacionalidades, (...) a riqueza das descrições sobre as diversas regiões do país e as inúmeras referências à vida cotidiana das populações, raras em outras fontes.

A obra objeto desta pesquisa, Viagem de Francisco Pyrard de Laval: contendo a notícia de sua navegação as Índias Orientais, Ilhas de Maldiva, Maluco, e ao Brasil, e os diferentes 
casos, que lhes aconteceram na mesma viagem nos dez anos que andou nestes países (1601 a $1611)^{3}$ foi elaborada em dois (02) tomos, assim divididos: o primeiro tomo com vinte e nove (29) capítulos e o segundo tomo com vinte e sete (27) capítulos. Neste sentido, procuraremos analisar as observações feitas por François Pyrard, da cidade de Laval, (1578-1623), transformadas em relatos escritos, uma vez que no próprio texto encontramos a referência à expressão Relações de viagem (PYRARD DE LAVAL, 1858:11, t.1). Por isso, mais uma vez nos aproximamos de Cláudia Santos (2013:21) que chama a atenção para a necessidade de se levar em conta que a escrita desses viajantes resultou da visão de um estrangeiro com o local visitado, daí o cuidado de se saber a conjuntura do seu país, quem era ele e as suas relações, os objetivos da viagem para que possamos dialogar com outras fontes e detectar a confirmação ou não dos seus relatos e até mesmo das denúncias encontradas durante a leitura.

Sem entrar em profunda discussão acerca da chamada crise do século XVII, mas apenas querendo circunscrever um panorama histórico para podermos compreender a saída do nosso Laval da sua terra, nos apoiamos, entre outros historiadores, em Trevor-Roper (2007: 131) para quem a conjuntura europeia no início do século XVII podia ser tipificada como uma crise geral nas relações entre sociedade e Estado:

Se, embora geral na Europa Ocidental, a crise do século XVII não é uma simples crise constitucional, nem uma crise de produção econômica, então que tipo de crise foi? Neste ensaio eu sugiro que, na medida em que foi uma crise geral - isto é, ignorando variações não gerais de um lugar para o outro -, ela foi um tanto mais ampla e vaga do que isso: de fato foi uma crise nas relações entre sociedade e Estado.

Valemo-nos de Eric Hobsbawm (1975: 56), destacando que “(...) a economia europeia passou por uma crise geral durante o século XVII, ultima fase da transição geral de uma economia feudal para uma economia capitalista", portanto centra sua análise na produção econômica. Fundamentamo-nos em Roland Mousnier (1957: 278) para quem a França enfrentava algumas dificuldades que podiam ter contribuído para que pessoas dos diferentes segmentos sociais quisessem se aventurar em busca de novas oportunidades ou mesmo de conhecer lugares e povos diferentes.

Na França, a luta pela independência contra as tentativas de hegemonia dos Habsburgo coloca o rei, incessantemente, em apuros financeiros. A produção deixa margens disponíveis muito reduzidas, o imposto é sempre insuficiente, o déficit é crônico e todo agravamento tributário é

3 PYRARD DE LAVAL, Viagem de Francisco Pyrard de Laval: contendo a notícia de sua navegação as Índias Orientais, Ilhas de Maldiva, Maluco, e ao Brasil, e os diferentes casos, que lhes aconteceram na mesma viagem nos dez anos que andou nestes países (1601 a 1611) 1858: Nova Goa: Imprensa Nacional, t. 1com 374 páginas e t. 2 com 400 páginas. 
duramente sentido. A carga fiscal torna-se depressa a razão, o motivo ou o pretexto de insurreições.

Neste contexto de alterações econômicas e sociais, Laval deixou S. Maló rumo às Índias Orientais (1601-1611). Entendemos como Russel-Wood que "foi o mar que deu sentido ao vasto mundo português, por isso o mar deve ser considerado o principal contexto desta história de um mundo em movimento" (RUSSELL-WOOD, 1998: 45) que resultou na circulação de homens/mercadorias desencadeado pela expansão europeia. Para este historiador, "os navios que partiam com destino à Índia e à América portuguesas transportavam um número considerável de pessoas (...) e no regresso vinham carregados de pimenta, especiarias, açúcar e ouro" (RUSSELL-WOOD, 1998: 92). Ressaltou, ainda que as embarcações tornaram-se verdadeiros instrumentos de trabalho na carreira da Índia e que o convés vinha apinhado de carga e um dos exemplos destas embarcações foi a Madre de Deus que foi capturada pelos ingleses quando regressava da Índia, em 1592 (RUSSELL-WOOD, 1998:46) e que por isso os portugueses recorreram a galeotas menores e mais velozes.

Outro momento histórico em que se inseriu o nosso viajante foi o da União das Coroas Ibéricas $^{4}$ em 1580. Após as mortes de D. Sebastião (1578), em confronto com os árabes e do cardeal D. Henrique, que assumiu o trono, surgiram outros candidatos: D. Catarina, a duquesa de Bragança, D. Antônio, o Prior do Crato e Filipe II rei da Espanha, filho de Isabel de Portugal e, portanto, neto de D. Manuel (1495-1521), o que lhe garantia direito ao trono. Destes, apenas Filipe II, D. Catarina e o Prior do Crato tinham chance a serem escolhidos, mas ainda assim, somente Filipe II e D. Catarina tinham bases jurídicas ${ }^{5}$ para as suas reivindicações, segundo Mattoso (1997: 469). Independente de quaisquer projetos anteriores ou posteriores a possessão do reino, como a criação do Reino Católico Universal, ideia presente desde Carlos V ${ }^{6}$ (SCHAUB, 2001: 15), o rei espanhol tinha o direito de sucessão neste caso.

A partir deste contexto acima se torna importante pensarmos se o que aconteceu com as duas coras foi uma anexação de território e um domínio espanhol ou se a assunção do trono de Filipe II pode ter sido aceita também por meio de acordos e por isso facilitou a união. Não

4 C.f Para outras importantes informações sobre a unificação dos reinos ibéricos, consultar entre outros autores, Elliot, J.H. España em Europa: estúdios de história comparada: Universitat de Valencia, 2002; Valladares, R. Portugla y La Monarquia Hispânica, 1580-1640. Madrid: Arcos Libros, 2000; Schaub, J. F. Portugal na Monarquia Hispânica (1580-1640). Lisboa: Livros Horizontes, 2001; Megiane, A. P.T. O rei ausente: festas e cultura política nas visitas dos Filipes a Portugal (1581 e 1619). São Paulo: Alameda, 2004.

5 Para D. Catarina seu direito estava embasado no iure hoereditário . Felipi II argumentava pelo direito das gentes e não pelo direito civil, como estava propondo a duquesa de Bragança. Para maiores detalhes consultar MATTOSO, José. História de Portugal - no alvorecer da modernidade (1480-1620), $3^{\circ}$ vol, Lisboa: Editorial Estampa, 1977.

6 C.f Schaub,ob cit, ressaltando que o sonho de uma monarquia católica universal estava presente desde o reinado de D. Manuel, o venturoso. 
vamos nos centrar nesta discussão, até porque esta pesquisa está se iniciando, mas não podemos deixar de registrar como estamos entendendo o que aconteceu. ${ }^{7}$

A historiografia considerava, antes da revisão, a União Ibérica como um domínio espanhol sobre Portugal. Valendo-nos da análise do historiador Schaub (2001: 51), compreendemos que o que houve foi uma união e não uma dominação de um reino sobre o outro.

nada há de mais parcial do que imaginar, nesta história, o frente-afrente entre uma potência activa, a monarquia hispânica, e outra passiva, a sociedade portuguesa. Redes sociais, corpos inteiros da sociedade portuguesa apostaram na capacidade da dinastia dos Habsburgo para tirar o reino da prostração em que o massacre de Alcácer-Quibir e o impasse dinástico da linhagem de Avis o haviam mergulhado.

John Elliott (2000:37) discorre em seu texto sobre as maneiras que, segundo Solorzano Pereira, jurista espanhol do século XVII, classificou em que circunstâncias os territórios poderiam unir-se a outros domínios reais: união accesoria e aeque principaliter, ${ }^{8}$ fundamentando a união aeque principaliter entre Espanha e Portugal a partir da vacância do trono.

Qué instrumentos estabam al alcance para conseguirlo? La coaccción em que El estabelecimiento de ciertas uniones modernas, como la de Portugal com Castilla em 1580, pero el mantenimiento de um ejército de ocupación era no solo um asunto costoso, como descubrieron em Irlanda lós ingleses , sino además podía ir en contra de misma política de integración que trataba de seguir la corona (...) Excluída una presencia militar más o menos permanente, las possibilidades se redicían a la creación de nuevos órganos institucionales em el nivel superior de gobierno y al uso del patronazgo para conseguir $y$ conservar la lealtad de las viejas elites políticas y administrativas.

O historiador Rafael Valladares (2000: 14-15) ressalta que sobre o reconhecimento do monarca espanhol pelos portugueses se fez pelas Cortes, por meio do Pacto de Tomar, (1581) e que "quella reunión sirvió también para establecer las condiciones em que la corona de

7 Utilizaremos os autores SCHAUB, J. F. Portugal na Monarquia Hispânica (1580-1640). Lisboa: Livros Horizontes, 2001. VALLADARES, R. Portugla y La Monarquia Hispânica, 1580-1640. Madrid: Arcos Libros, 2000.

8 Segundo Solorzano Pereira pela união accesoria um reino ou província, em união com outro, passava a ser considerado juridicamente como parte integral dele, possuindo seus membros os mesmos direitos e estavam sujeitos as mesmas leis. O exemplo deste tipo de união com a Monarquia espanhola foram as Indias Ocidentais incorporadas à Coroa de Castela. Pela união aeque principaliterem os reinos constituintes continuavam depois de sua união sendo tratados como entidades distintas, mantendo suas próprias leis, foros e privilégios. 
Portugal permaneceria agregada al imperio español". Entre os acordos, estavam “(...) el pleno reconocimiento al particularismo regnícola de Portugal en seno de la Monarquia; (...) los otros acuerdos , miraban a confirmar los privigégios de la nobleza y de la iglesia (...)”. Neste sentido, referiu-se o autor a algumas das exigências portuguesas à ascensão de Filipe II ao trono, ou seja, a preservação da estrutura administrativa de Portugal e ao exclusivismo comercial com as colônias.

Schaub (2001: 21-22) argumenta que sobre a aceitação da união das Coroas "o novo rei prometia não suprimir nenhuma função ou ofício do aparelho monárquico português no qual sucedia e garantia aos seus súditos a exclusividade total das futuras nomeações”. E conclui que "a entrada da coroa portuguesa na monarquia hispânica só pode ter sido representada como uma saída por cima para a crise porque existiam conivências profundas entre as sociedades portuguesas e castelhana" como, por exemplo, "a troca de poderosas garantias - nobreza, clero e oligarquias urbanas tinham a oportunidade de negociar a confirmação e o acréscimo dos seus privilégios e benefícios" (SCHAUB, 2001: 51). Portanto, o nível de negociações existentes para além das questões dos títulos na ordem de sucessão, a autoproclamação de Dom Antônio, "as cidades sob a pressão das armas ou por mera convicção, renderam homenagem a Filipe II" (2001: 16). Portanto, ancorado em acordos com a nobreza portuguesa e suas Cortes, Filipe II finalmente é declarado rei de Portugal em 1580.

François Pyrard, residente na zona de Laval em França, filho e neto de comerciantes, partiu do porto de Saint-Malo, em 18 de maio de 1601 (PYRARD DE LAVAL, 1858: 5, t. 1), a bordo do corsário Corbin, na condição de marinheiro, "não menos desejoso de ver e de aprender, do que de adquirir cabedal, embarquei-me no Corvo" (PYRARD DE LAVAL, 1858: 2, t. 1) na esperança de ensinar aos companheiros de viagem os caminhos das riquezas do Oriente.

O que motivou a aventura, segundo Laval, foi o descontentamento dos franceses com o monopólio que portugueses e espanhóis exerciam sobre os mares, as regiões e as mercadorias que estavam sob os seus domínios. Então, Laval e uns mercadores de S. Maló que criaram uma companhia equiparam dois navios, o Crescente e o le Corbin e resolveram "sondar o vão, buscar o caminho das Índias, mostra-lo aos franceses em somma beber na própria fonte" (PYRARD DE LAVAL, 1858:2, t. 1).

O destino da embarcação era às Índias Orientais, Ilhas de Maldiva, Ilhas Maluco e Brasil e que durou dez anos, até 1611. Narra, Laval, a difícil travessia pelo Cabo da Boa Esperança e toda sorte de intempéries que sofreram até chegarem à costa da Etiópia. Ressalta o dissabor de, possivelmente, terem perdido o navio Crescente, nos conta do naufrágio do Corvo, em julho de 1602, até a chegada nas Ilhas Maldivas. Ali se torna cativo do rei de Paindué onde permanece por um período de cinco anos, de 1602 até 1607 (PYRARD DE LAVAL, 1858: 41-60, t. 1). Conseguiu perceber o prisioneiro a importância que o comércio tem para o rei das Maldivas, e de quanto são valorosas as moedas de prata neste local. Esta moeda é, ali, mais 
estimada do que as de ouro. Também afirma o quanto valorizam naquela terra os reales de prata advindos da Espanha e de suas colônias. Relata que o comércio das Maldivas é feito com mercadores do Ceilão, Sumatra, Cochim, Cananor, Calicute, Arábia, Bengala, S. Thomé, Onor, Bangalor e adjacências (PYRARD DE LAVAL, 1858: 194, t. 1).

Quando conseguiu fugir entrou em contato com os portugueses da colônia de Cochim (Índia) e foi enviado como prisioneiro para Goa, (PYRARD DE LAVAL, 1858: 375, t.1) onde permaneceu nesta condição (PYRARD DE LAVAL, 1858: 18, t.2). Entretanto, pela falta de efetivos para a defesa de Goa e "para dar guarda aos navios mercantes" ressalta o navegador que esteve "em Goa com os portugueses por espaço de dous annos, recebendo paga de soldado e indo em várias partes em suas expedições” até 1610 (PYRARD DE LAVAL, 1858: 122123, t. 1).

Neste ano de 1610 embarcou Laval junto com outros estrangeiros, (PYRARD DE LAVAL, 1858: 242, t.2) por ordem do vice-rei de Goa, na nau Nossa Senhora de Jesus. Após navegarem e chegarem a ilha de Santa Helena, um acidente com a embarcação fez com que acordassem que o rumo seria a "(...) à Bahia de Todos os Santos, cidade capital do Brazil, onde tem seu assento o Vice-Rey português" (PYRARD DE LAVAL, 1858: 263, t. 2), até chegarem ao seu destino final, a Europa. Destas viagens resultaram os relatos onde registra os hábitos, os costumes, as leis, a organização das cidades e os aspectos arquitetônicos, a conduta social desde os mais altos cargos até os escravos e artesãos que trabalhavam para os portugueses, os recursos naturais, as práticas agrícolas e o fluxo comercial dos locais por onde passou, assim escreve que identificou sinais de atos ilícitos.

O propósito dessas notas de pesquisa é, por se tratar de uma pesquisa em início de desenvolvimento, destacar, a partir das informações de François Pyrard durante as suas viagens, inclusive ao Brasil, os recursos da terra, aqui encontrados e comercializados, no contexto de uma história que contemplou a época da chegada dos Filipes ao trono espanhol e a agregação de Portugal a esta monarquia, em 1580, como afirmamos anteriormente.

Raminelli (2008: 36) chama a atenção para o fato de que esta união das Coroas Ibéricas "suscita a modernização do sistema político português, ao recorrer a reformas que alteraram tanto a comunicação política administrativa entre o rei e o reino quanto às modalidades do exercício do poder". Neste sentido, podemos lembrar não só das Ordenações Filipinas (1603) que davam sustentação legal para o fomento da produção agrícola na colônia, mas também do Regimento do Pau-brasil (1605), uma legislação específica para exploração desta madeira, diferente de todas as suas predecessoras, pois sistematizava a exploração e não apenas mencionava a questão como outros documentos político-administrativos da colônia.

Nas suas viagens, Laval destacou o comércio da China e do Japão e o quanto o tráfico comercial nestas regiões era de importância não só para as Índias Orientais, inclusive para 
Goa (principal rota de escoamento dos produtos comerciais daquela região), como também para Portugal.

(...) ora sendo a cidade de Goa o logar onde se faz a carga e descarga das mercadorias de todas as partes da Índia e de Portugal segundo o regimento d'El Rey, o Vice-Rei envia dalli todos os annos dous ou três navios China e Japão, dos quaes uns vão somente à China e outros a uma outra parte. Por China entenda-se somente Macáo, que é uma ilha e cidade onde estam os Portugueses (...) e é alli a escala e o desembarcadouro de todas as mercadorias que vem assim da China como das outras partes do mundo (PYRARD DE LAVAL, 1858: 150-151, t. 2).

Laval chama a atenção para o tráfico exclusivo dado aos portugueses no comércio das Índias Orientais e de como o rei da Espanha punia as outras nações que ali se aventurassem afirmando que este privilégio foi concedido por ele, porque senão seria a ruína de Portugal:

O principal tráfico dos portugueses é nas Índias Orientais onde elles não querem consentir que alguma outra nação, nem ainda os hespanhóis vão tratar e isto é estreitamente defeso por El-Rei sob pena de morte (PYRARD DE LAVAL, 1858: 179, t.2).

Neste sentido, Laval ressalta que os portugueses conseguiram se tornar "donos" na forma de todos os tratados e acertos feitos junto aos reis das vizinhanças, do mar da Índia e que ninguém,

da terra firme como das ilhas de qualquer região que fosse ousassem navegar nem fazer viagem alguma, sem ter passaporte seu, o qual dura um só anno; e estes passaportes que chamam Cartazes, levam cláusula de que elles não poderão navegar senão para certas partes alli declaradas e ainda para essas não poderão levar pimenta, armas e munições de guerra, com declaração especial de quantas armas e homens podem levar e se lhes acharem mais do que é dito (...) tudo é confiscado e julgado boa preza, ficando de mais a mais a gente do navio cativa (...) (PYRARD DE LAVAL, 1858: 182, t.2).

Contudo, faz a ressalva para os reis amigos dos portugueses aos quais não são postos "freios", mas chama a atenção para o fato de que não estavam imunes aos atos ilícitos que pudessem acontecer nessas transações. 
podem enviar certo número de navios onde bem quiserem com carga de qualquer mercadoria sem que ninguém possa tomar-lhes disso conta, e até não são obrigados a tirar Cartaz; todavia tiram-nos para os mercadores das suas terras de quem ficam como fiadores, o que dá occasião a que debaixo do seu nome passem muito com carga de pimenta e outras mercadorias a Arábia (...) (PYRARD DE LAVAL, 1858: $183, \mathrm{t} .2)$.

Nosso navegador permaneceu em Goa, de 1608 a 1610, regressando à Europa a bordo de uma nau de Carrera da Índia - Nossa Senhora de Jesus - (PYRARD DE LAVAL, 1858: 242-255, t.2) e, nos seus relatos, fez referências aos hábitos dentro daqueles navios bem como ao transcurso percorrido. Depois das intempéries passadas pela nau, Laval informou que iriam se dirigir ao Brasil. A entrada da nau em águas da colônia brasileira foi descrita assim:

a 8 de agosto começamos a avistar a terra do Brazil que é mui branca e parece como lençóes e toalhas que estam a enxugar, ou antes neve (...). No dia 9 do mesmo mês (...) ficamos "fora da entrada daquela bahia na qual não ousamos entrar por não a conhecermos (...) pelo que enviamos a lancha (...) a dar aviso ao Vice-Rei [governador-geral] da nossa chegada (...). Vindo a noite fogos de sinal que significavam que nos vinham de socorro trez caravellas carregadas de refrescos e traziam pilotos para nos guiar (...) foi grande o nosso contentamento tanto mais que havia seis mezes inteiros que éramos partidos de Goa (...). A dez do mês pela manhã (...) saudamos a cidade e o Vice-Rei a tiros de artilharia e semelhante o Vice-Rei [governador-geral] nos mandou dar uma salva de toda a sua artilharia (...). E, logo, (...) o Vice-Rei mandou vir embarcações para recolher a gente e a fazenda (...), o navio ficou alliviado e começou a fluctuar e nós chegamos para debaixo das artilharias da cidade que se chama de São Salvador (...) (PYRARD DE LAVAL, 1858: 265-266, t.2).

E para completar o ritual da chegada, Laval e seus companheiros, ao desembarcarem, foram procurar o governador-geral do Brasil (a que chamavam de Vice-Rei) para quem mostraram o "passaporte assignado pelo Vice-Rei e Vedor da Fazenda de Goa" e acrescenta que "elle tendo-o visto, nos recebeo com bastante cortezia e nos disse que viéssemos comer e beber a seu aposento, e até dormir, se quiséssemos" (PYRARD DE LAVAL, 1858: 280, t.2). Todo esse ritual serviu para dispersar o temor que os portugueses tiveram com a chegada desta nau, pois pensaram que o motivo desta presença era para lhes fazer guerra.

Após a chegada ao Brasil, Laval se deteve a descrever a cidade de Salvador nos seus mais variados aspectos físicos e culturais, observando que a maioria dos recursos aqui encontrados eram passíveis de venda, sem restrição, menos o pau-brasil: 
o que os portugueses pois extrahem deste paiz é dinheiro, (...), conservas, balsamo e tabaco e não páo brazil, que El-Rei de Hespanha reserva para si (...), e há-o lá em muita abastança e ninguém ousaria tratar nelle, porque achado n'um navio pouco ou muito, que não fosse comprado a El-Rei, o navio seria confiscado (...) (PYRARD DE LAVAL, 1858: 270, t.2).

Laval fez referência em outra passagem da licença concedida pelos senhores da terra para se cortar o pau-brasil com o objetivo de se alimentar o fogo das caldeiras dos engenhos.

há senhores que possuem grandes territórios e nelles muitos engenhos de assucar, (...) e esses senhores dão terras a quem que ir morar nellas e plantar cana de assucar, com a condição de mandarem moer estas aos moinhos dos mesmos senhores, pagando-lhes um tanto (...). Também dão licença de cortar lenha para o fogo das caldeiras dos engenhos pagando-lhes tanto como se a fossem buscar a outra terra. (PYRARD DE LAVAL, 1858: 271, t.2).

A partir deste relato, percebemos que o viajante nos fornece indícios de que em alguma parte da região a lei estava sendo descumprida. A legislação sobre a exploração do pau-brasil de 1605 (MENDONÇA, 1972: 364), além de proibir a queima das matas para se fazer roçados e ao contratador deixar paus cortados pelo caminho, descarta a utilização desta madeira para aqueles fins, além de exigir dos colonos que fizessem a diferença entre as árvores plantadas. Isto porque a Coroa queria "proteger" as árvores de pau-brasil com o objetivo de conservar para explorar.

Para o nosso viajante, a fonte de maior riqueza da Coroa era o açúcar, fato que não estava longe de ser verdadeiro neste século XVII.

É uma terra mui áspera e bravia, quase toda coberta de bosques; e até mui perto e em volta das cidades todos estes bosques são cheios de bugios e monos, que fazem muito damno (...). A riqueza desta terra é principalmente em assucares, dos quais (...) os Portugueses carregam seus navios. Porque não julgo que haja logar em todo o mundo, onde se crie assucar em tanta abundancia como alli (PYRARD DE LAVAL, 1858: 269, t.2).

O historiador Stuart Schwartz (1988: 95) ressalta que a economia açucareira foi responsável pela criação do contexto da vida baiana, quer seja "nas relações políticas e 
econômicas de seus administradores e cidadãos, por meio dos impostos, tarifas, limitações governamentais ao crescimento, preços de escravos, restrições e condições comerciais," quer seja "no aparecimento dos agricultores como categoria social e as relações desenvolvidas com seus credores comerciantes". Enfim, a produção dos engenhos permaneceu como a principal cultura de exportação do Recôncavo, apesar de haver procura não só por parte da Coroa, mas também de outros proprietários por outras fontes de renda na região.

Mencionou Laval o pouco conhecimento dos franceses em relação às possibilidades de produção açucareira da colônia portuguesa da América. Comparou o número de engenhos daqui com a produção de açúcar das ilhas da Madeira e de São Tomé mostrando que, aos seus olhos, aqui temos mais terras e engenhos, o que nos colocava em posição de maior destaque econômico:

\begin{abstract}
Não se falla em França senão do assucar da Madeira e da Ilha de S. Thomé, mas este é uma bagatela em comparação da do Brasil, porque na Ilha da Madeira não há mais de sete ou oito engenhos a fazer assucar, e quatro ou cinco na Ilha de $\mathrm{S}$. Tomé. Mas segundo meu próprio conhecimento há no Brasil, em cento e cincoenta legoas de costa, perto de quatrocentos engenhos (...) que se compreendem desde vinte e cinco legoas para cá de Pernambuco, até vinte e cinco legoas para lá da Bahia de Todos os Santos (PYRARD DE LAVAL, 1858: 270, t.2).
\end{abstract}

O olhar deste navegador não era impreciso em relação a esta questão da riqueza desta prática agrícola porque a Baia de Todos os Santos foi um dos locais onde a produção açucareira mais floresceu segundo Vera Ferlini. E, a afirmação de Laval de que havia, em 1610, cerca de quatrocentos engenhos espalhados pela costa brasileira, fazia todo sentido, uma vez que, em 1584, "só no Recôncavo Baiano atingia-se o número de quarenta unidades de engenho" (FERLINI, 1984: 25), o que nos leva a crer que no início do século XVII pudéssemos ter atingido aquele número, tendo em vista o objetivo da Coroa voltado para o comércio.

Para Laval (1858: 270, t.2) “esta terra do Brazil é pois tão má que seria impossível habitala e permanecer ahi por muito tempo, se não fora este trafico dos assucares e do pão." A observação de Laval vai ao encontro do que, provavelmente, observava em relação ao comércio que se fazia à revelia das autoridades locais e da Coroa, pois o que ele sustenta na sua narrativa são as práticas ilícitas de comércio, ou sejam, fora das regulamentações para a exploração dos recursos para se sobreviver na terra. No entanto, não percebeu que o que estava velado nesta situação era o resultado do jogo de pressões e contrapressões a que a metrópole e colônia estavam submetidas e que o tráfico a que ele se referiu estava relacionado, muitas vezes ao contexto geral da exploração por isso os colonos procuravam 
encontrar dentro do sistema ${ }^{9}$ imposto, um caminho que melhor se adaptasse aos seus anseios.

Julgando que o que se plantava aqui como o "arroz, milho, grosso e miúdo, raízes de mandioca, batatas" ou o que havia nos engenhos como "plantações de toda sorte de fructos; muito gado, aves e outros comestíveis era suficiente para a sustentação de todas as guarnições do Vice-Rei, Governadores, capitães, soldados", (PYRARD DE LAVAL, 1858: 271272, t.2) não via a necessidade do envio de dinheiro de Portugal para os gastos com esses funcionários, além do que o rei da Espanha tirava da terra a cada ano muito proveito. Ainda para reforçar esta situação, relatou Laval que "também se faz neste paiz grande quantidade de óleo de baleia, especialmente na Bahia de Todos os Santos e que dele se faz mui grande tráfico", afirmando que se tem muito dinheiro aqui e que vem "todo do Rio da Prata", (PYRARD DE LAVAL, 1858: 272, t.2) o que nos remete a relação comercial, suspeitosamente apontada, da colônia brasileira com esta região.

Outras duas atividades de plantio são arrolados em suas narrativas, o gengibre e o tabaco. Estes recursos, encontrados em abundância, aqui na terra, e comercializados também foram contabilizados para o enriquecimento daqueles que permaneceriam aqui por muito tempo, como concluiu Laval: "depois de haverem estado nove ou dez annos nestas terras, recolhem mui ricos". Neste sentido, acrescentou que "há alli entre outros, muitos christãos novos que são judeus baptisados, que tem de seu o cabedal de sessenta, oitenta e cem mil cruzados, e mais; mas elles não fazem grande conta desta gente" (PYRARD DE LAVAL, 1858: 272, t.2), numa explícita referência ao atrativo que o comércio de mercadorias aqui da colônia exercia, como também a possibilidade de enriquecimento lícito ou ilícito desses cristãos novos.

Laval retrata a experiência vivenciada com a mandioca, pois que "fazem certa farinha [d'uma raiz chamada Mandioca], que comem e da qual se alimentam". E, para surpresa dele, "é gostosa e come-se pisada em migalhas com a carne", e acrescentou: "vivi della por espaço de seis mezes em logar de pão" (PYRARD DE LAVAL, 1858: 272, t.2).

Nos seus relatos encontramos alusão ao fluxo de moeda de prata na colônia, em um deles, o viajante afirma que "nunca vi terra onde o dinheiro seja tão comum", demonstrando estranheza quanto à procedência pois,

9 C f. Fernando Novais chama atenção para o fato de que o sistema colonial pode ser visto pelo fenômeno da colonização "resultado do alargamento de expansão humana no globo, pela ocupação, povoamento e valorização de novas regiões, (...) que se dá nas mais diversas situações históricas e que nos Tempos Modernos tal movimento se processa travejado por um sistema específico de relações, assumindo a forma mercantilista de colonização (...). E, na p. 144 que este "Antigo Sistema Colonial, na realidade, era parte de um todo, que se explica nas suas correlações com esse todo: o Antigo Regime (absolutismo, sociedade estamental, capitalismo comercial)". 
vem do Rio da Prata, que é a quinhentas legoas desta Bahia. Não se vê alli moeda meuda, mas somente peças de cinco soldos; e procuram em Portugal as moedas de cinco soldos e de seis brancos para as vender alli por moeda meuda e nisso tiram proveito; porque usam mui pouco outra moeda afora a de prata (PYRARD DE LAVAL, 1858: 271, t.2).

Esta estranheza nos faz pensar que ele percebia indícios de descaminho nas relações comerciais estabelecidas entre colônias americanas. E, destes desgovernos e descaminhos, Laval cita casos ao longo da sua estadia aqui no Brasil, entre eles, o do francês Julião Miguel que se passou por espanhol, tornando-se sócio de um português que tinha licença do rei para a pesca da baleia. Entretanto, para nosso viajante, o objetivo do francês/espanhol estava dirigido a comerciar o pau-brasil. Situação fora da ordem estabelecida pela Coroa, porque desde o início da colonização, encontramos no Foral de Duarte Coelho a indicação expressa de que

(...) o pau-brasil da dita capitania (...) pertencerá a mim, e será tudo sempre meu e de meus sucessores (...) o pau-brasil da dita capitania e assim qualquer especiaria ou drogaria (...) nem as poderão vender nem tirar (...) para fora deles [reinos], sob pena de quem o contrário fizer perder (...) toda sua fazenda (...) e ser degredado (...) (MENDONÇA, 1972: 126).

E, com na vigência do regimento de 1605 , reiterava-se mais uma vez a impossibilidade de estrangeiros fazerem o comércio da madeira:

Primeiramente hei por bem, e mando que nenhuma pessoa possa cortar, nem mandar cortar, o dito pau-brasil, por si, ou seus escravos ou feitores seus, sem expressa licença ou escrito do provedor-mor de minha Fazenda, de cada uma das capitanias, em cujo distrito estiver a mata, em que houver de se cortar (...) (MENDONÇA, 1972: 363-364).

Assim como a licença de exploração seria concedida às pessoas consideradas idôneas, tomando o provedor-mor, "informação da qualidade da pessoa que lha pede e se dela há alguma suspeita [de] que o desencaminhará ou furtará ou dará a quem o haja de fazer" (MENDONÇA, 1972: 363-364).

Diante desses e de outros indícios, a viagem de Pyrard de Laval, em se tratando de suas viagens ao Oriente e de suas observações sobre o Brasil, se transformaram num tratado descritivo da terra em seus mais variados aspectos, identificando características peculiares de cada lugar, as potencialidades da produção agrícola, os recursos naturais disponíveis e a 
dinâmica das transações comerciais (lícitas ou não). Dessa maneira, esperamos em trabalho futuro nos debruçarmos sobre essa importante obra. Não apenas discutindo as suas possibilidades de análise, mas observando detidamente a relação da obra com o contexto geral da política filipina para a colônia brasileira, os atores envolvidos nos possíveis casos de descaminho dos recursos da terra e as "soluções" pensadas pelas autoridades e legisladores da época.

\section{Bibliografia}

ELLIOTT, John H. Uma Europa de monarquias Compuestas. In: España em Europa. Estúdios de História Comparada. València: Universidad de València, 2002.

FERLINI, Vera Lúcia Amaral. A civilização do açúcar. Séculos XVI a XVIII. São Paulo. Brasiliense,1984.

HOBSBAWM, Eric. A Crise Geral da Economia - Da economia europeia no século XVII. São Paulo: Eldorado, 1975.

MENDONÇA, Marcos Carneiro de. Raízes da formação administrativa do Brasil (Regimento do Pau-Brasil). Rio de Janeiro: IHGB e Conselho Federal de Cultura, 1972).

MOUSNIER, Roland. Os Séculos XVI e XVII. São Paulo: Eldorado, 1957.

NOVAIS, Antônio Fernando. Portugal e Brasil na crise do Antigo Sistema Colonial (17771808). $2^{\text {a }}$ ed. São Paulo: Hucitec, 1983.

PYRARD DE LAVAL, Francisco. Viagem de Francisco Pyrard de Laval: contendo a notícia de sua navegação as Índias Orientais, Ilhas de Maldiva, Maluco, e ao Brasil, e os diferentes casos, que lhes aconteceram na mesma viagem nos dez anos que andou nestes países (1601 a 1611). Nova Goa: Imprensa Nacional, 1858.

RAMINELLI, R. Viagens ultramarinas: monarcas, vassalos e governo à distância. São Paulo: Alameda, 2008.

RUSSELL-WOOD, A. J. R. Um Mundo em Movimento. Os Portugueses na África, Ásia e América (1415-1808). Lisboa: Difel, 1998.

SCHAUB, J. F. Portugal na Monarquia Hispânica (1580-1640). Lisboa: Livros Horizontes, 2001.

SCHWARTZ, B. Stuart. Segredos Internos: engenhos e escravos na sociedade colonial. São Paulo: Cia das Letras, 1988. 


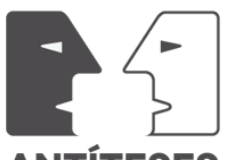

ANTÍTESES

TREVOR-ROPER, Hugh. R. A Crise Geral do século XVII. Rio de Janeiro: Topbooks, 2007.

VALLADARES, R. Portugal y La Monarquia Hispânica, 1580-1640. Madrid: Arcos Libros, 2000.

Texto recebido em 5 de dezembro de 2013 e aprovado em 26 de março de 2014 